\title{
The observation of the sedation effects of intranasal methods of dexmedetomidine for magnetic resonance imaging in children
}

\author{
Shuang Qi ${ }^{1}$, Suming $\mathrm{Wu}^{2}$ and Feng Liang ${ }^{1, a}$ \\ ${ }^{1}$ China-Japan Union Hospital of Jilin University \\ ${ }^{2}$ The $4^{\text {th }}$ Hospital of Jilin University(The General Hospital of FAW)
}

\begin{abstract}
To compare the sedation effects of two intranasal methods of dexmedetomidine for magnetic resonance imaging (MRI) in children. Method: 40 children for MRI were randomly divided into two groups, namely 20 cases for each group: nasal drip group(group A)and nasal spray group(group B). Group A and group B received intranasal dexmedetomidine of $1.5 \mathrm{ug} / \mathrm{kg}$ by two methods. Monitoring the $\mathrm{HR}, \mathrm{SpO}_{2}, \mathrm{RR}$ and inspection time of the two groups so as to observe the sedation effects and Ramsay sedation score while recording the adverse reactions. Results: There was no significant difference in the HR, $\mathrm{SpO}_{2}$, $R R$ between the two groups at the same time point $(\mathrm{P}>0.05)$. Compared with group $\mathrm{A}$, the timeto-fall-asleep in group $B$ was shorter and the adverse reactions significantly decreased $(\mathrm{P}<0.05)$.Conclusion: Compared with nasal drip,nasal spray dexmedetomidine by MAD can shorten the time-to-fall-asleep and reduce adverse reactions for MRI in children.
\end{abstract}

\section{Introduction}

Magnetic resonance imaging (MRI) is an effective diagnostic method to identify diseases, but its testing time is long with large instrument noise, so most of the children patients show poor obedience. Light activity of children will lead to artifacts or false appearances which will affect the accuracy of diagnosis. Besides, the cost of MRI is relatively high and repeated inspections will increase economic burden to parents, so rational use of sedative drugs is an important part to guarantee a smooth MRI for children. Mason et al. ${ }^{[1]}$ studied and confirmed the sedative advantages of dexmedetomidine for MRI in children. The research of domestic scholars ${ }^{[2]}$ confirms that dexmedetomidine nasal drip of 2-5 years old children can achieve good sedative effect. But the optimal dose and methods of nasal administration still need further discussion. Therefore, this study aims at comparing the sedation effects of two intranasal methods of dexmedetomidine for MRI in children.

\section{Materials and Methods}

\section{1 General Data}

From January to December of 2015, 40 children accepted MRI examinations in China-Japan Union Hospital of Jilin University. Those children were aged at 2-5 years old and their sex was unlimited.

\footnotetext{
${ }^{a}$ Corresponding author: 295253720@qq.com
} 
Their BMI is 17.0 to $24.0 \mathrm{~kg} / \mathrm{m}^{2}$, classified as grade I to II by ASA. There was no abnormality with their nasal cavity structure and no damage to their nasal mucosa. The children had no sedation taboos, allergic history of dexmedetomidine or respiratory and circulatory system diseases. They were randomly divided into the group of dexmedetomidine administration by nasal drip (group A) and group of dexmedetomidine administration by nasal spray (group B).

\section{2 The Administration Methods}

The two groups of children patients got fasted routinely before medication. They were placed at the supine position. Extracting $1 \mathrm{ml}$ dexmedetomidine (the batch number: 15051332; Jiangsu Hengrui Pharmaceutical Co., Ltd; the concentration is $100 \mathrm{ug} / \mathrm{ml}$ ) and administrating the dose of $1.5 \mathrm{ug} / \mathrm{kg}$ by their parents to the nasal cavity of children at the presence of anesthesiologists. Group A used $1 \mathrm{ml}$ syringes without needles for nasal inhalation; group B used MAD (model: MAD100, Wolfe Tory Pharmaceutical Co., Ltd.) for nasal spray. Parents administrated to both left and right nostrils alternately with equal drug. Observing the children patients' reactions until they fell asleep and then making positioning scanning. Keeping monitoring their $\mathrm{HR}, \mathrm{SpO}_{2}$ and $\mathrm{RR}$ after medication.

\section{3 Observation Index}

Observing the cooperative degree of the two groups of children during medication. Using Ramsay grading method to measure the sedation effects.1point: restlessness; 2 points: cooperating quietly; 3 points: having responses to commands; 4 points: drowsiness with sensitive reactions to loud acoustic stimulation; 5 points: drowsiness with slow reactions to loud acoustic stimulation; 6 points: drowsiness without any response. 2-5 points is moderate sedation. Recording the fall-asleep time of both groups of children (administrating drugs to the time graded by 2-5 points according to Ramsay). Comparing the $\mathrm{HR}, \mathrm{SpO}_{2}$ and $\mathrm{RR}$ before medication $\left(\mathrm{t}_{0}\right)$ and 20 min after medication $\left(\mathrm{t}_{1}\right)$. Recording the incidence of crying, bucking, respiratory depression $\left(\mathrm{SpO}_{2}<90 \%\right.$ is regarded as existing respiratory depression), nausea and vomiting and other adverse reactions.

\subsection{Statistical Treatment}

SPSS 13.0 statistical software is adopted for data analysis. The enumeration data is tested by $\chi^{2}$. The measurement data is expressed by mean standard deviation $(\bar{X} \pm S)$. The intra-group comparison is tested by matching t; intra-group comparison is analyzed by one-way variance, $\mathrm{P}<0.05$ meaning significant differences.

\section{Results}

The general data and inspection time of the two groups of children patients had no statistical differences $(\mathrm{P}>0.05)$, as shown in table 1. The HR, $\mathrm{RR}$ and $\mathrm{SpO}_{2}$ before and after medication had no statistical differences $(\mathrm{P}>0.05)$, as shown in table 2. Compared with group $\mathrm{A}$, the fall-asleep time of children of group B is shortened and the occurrence of crying and bucking is reduced $(\mathrm{P}<0.05)$, are shown in table 3.

Table 1 The comparison of general data and inspection time of the two groups of children patients

\begin{tabular}{cccccc}
\hline Groups & $\begin{array}{c}\text { Case } \\
\text { Number }\end{array}$ & Male/Female & Age & BMI & Inspection Time \\
\hline Group A & 20 & $11 / 9$ & $3.52 \pm 1.46$ & $20.51 \pm 3.42$ & $30.52 \pm 10.27$ \\
Group B & 20 & $10 / 10$ & $3.46 \pm 1.54$ & $21.27 \pm 3.64$ & $31.46 \pm 9.87$ \\
\hline
\end{tabular}


Table 2 The comparison of the HR, RR and $\mathrm{SpO}_{2}$ before and after medication of the two groups of children patients $(\bar{X} \pm S, \mathrm{n}=20)$

\begin{tabular}{cccc}
\hline Items & Groups & Before Medication $\left(\mathrm{t}_{0}\right)$ & After Medication $\left(\mathrm{t}_{1}\right)$ \\
\hline $\mathrm{HR}$ & Group A & $123.32 \pm 6.46$ & $120.43 \pm 6.23$ \\
$(/ \mathrm{min})$ & Group B & $121.18 \pm 6.56$ & $116.39 \pm 4.06$ \\
$\mathrm{RR}$ & Group A & $24.12 \pm 1.13$ & $23.67 \pm 0.92$ \\
$(/ \mathrm{min})$ & Group B & $23.82 \pm 0.97$ & $22.12 \pm 1.10$ \\
$\mathrm{SpO}_{2}$ & Group A & $99.23 \pm 0.38$ & $99.07 \pm 0.65$ \\
$(\%)$ & Group B & $99.11 \pm 0.47$ & $98.32 \pm 0.46$ \\
\hline
\end{tabular}

Table 3 The comparison of fall-asleep time and adverse reactions of the two groups of children patients $(\bar{X} \pm S, \mathrm{n}=20)$

\begin{tabular}{cccccc}
\hline Groups & $\begin{array}{c}\text { Fall-asleep- } \\
\text { Time } \\
(\mathrm{s})\end{array}$ & Crying & Bucking & $\begin{array}{c}\text { Adverse Reaction } \\
\text { Respiratory } \\
\text { Depression }\end{array}$ & Nausea and Vomiting \\
\hline $\begin{array}{c}\text { Group } \\
\text { A }\end{array}$ & $18.4 \pm 3.8$ & 5 & 7 & 0 & 0 \\
$\begin{array}{c}\text { Group } \\
\text { B }\end{array}$ & $14.3 \pm 4.1^{*}$ & $1 \Delta$ & $1^{\#}$ & 0 & 0 \\
\hline
\end{tabular}

Compared with group $\mathrm{A}, \mathrm{P}^{*} \Delta^{\#}<0.05$

\section{Discussion}

In order to obtain a satisfying image during MRI, effective measures are usually taken on incoordinate children to make sure they are quiet in the process of scanning. As it only requires stopping movements with low analgesia, so moderate sedation, namely conscious sedation, is mainly adopted. The medication method of out-patient examination for children is mainly orally taking or enema ${ }^{[3-4]}$, but due to the drug taste, operating techniques and the fear of a strange environment, orally taking or enema easily leads to crying and restlessness of children patients, so reasonable and comfortable way of medication is an important link for the sedation of children.

Administering drugs by the intranasal route is a simple and convenient way commonly used on children. It can be done by the most familiar people of children, so it is easier for children to accept. Besides, this method can also reflect the development trend of comfort and humanized medical science. Dexmedetomidine is a new-type, efficient and high-selectivity $\mathrm{a}_{2}$ adrenoceptor agonist. Compared with other sedative drugs, it takes a quicker effect with no respiratory depression and has mild effect of analgesia. In addition, it is colorless and tasteless without any mucosa stimulation. Its concentration is higher in unit dose. Therefore, it is more suitable for nasal route ${ }^{[5]}$. The study finds that, the vital signs of the two groups of children is stable and they are calm moderately without adverse reactions such as respiratory depression, nausea, vomiting and restlessness if administrating dexmedetomidine through transnasal method.

Different with common syringe intranasal methods, MAD can make the drug liquid evenly disperse into tiny droplets and then they will adsorb on the nasal mucosa, which strengthens the absorption concentration of drugs to the utmost extent.The result of this study confirms that administering dexmedetomidine to nasal cavity by MAD can effectively shorten the fall-asleep time of children patients in comparison with ordinary nasal inhalation conducted by ordinary syringes. When dripping nose with ordinary syringes, children patients are easily to have adverse reactions such as bucking and crying ${ }^{[6]}$. The results of the study also verifies that administering dexmedetomidine to nasal cavity by MAD can effectively reduce the incidence of adverse reactions. Thus, children patients will feel more comfortable during sedation. 
In conclusion, compared with traditional ways of nasal inhalation, administering dexmedetomidine to nasal cavity by MAD in MRI examination can significantly shorten the fall-asleep sleep and reduce the occurrence of adverse reactions, so it is worthy of popularization and application in clinic.

\section{References}

1.Mason KP,Robinson F,Fontaine P, Radiology, 267,911 (2013)

2.Jia JE, Chen Y, J Clin Anesthesiol, 28, 1172 (2012)

3.Krauss B,Green SM,Lancet,367,766 (2006)

4.Yuen VM,Hui TW,Irwin MG,Anesm Analg,106,1715 (2008)

5.Yuen VM, Irwin MG, Hui TW, Anesth Analg, 105, 375 (2007)

6.West SK,Griffiths B,shariff Y,Br J ophthalmo,97,1438 (2013) 